\title{
Enhanced performance of CdS/CdSe quantum dot- sensitized solar cells by long-persistence phosphors structural layer
}

\author{
Yunlong Deng, Shuqi Lu, Zhiyuan Xu, Jiachi Zhang, Fei Ma ${ }^{*}$ and Shanglong Peng*
}

\begin{abstract}
Light absorption plays an important role in improving the power conversion efficiency (PCE) of quantum dot-sensitized solar cells (QDSSCs). In this study, a multifunctional long-persistence phosphor (LPP) layer was introduced into the CdS/CdSe QDSSCs via a simple doctor blade method. The LPP layer can simultaneously improve the light harvesting and photo charge transfer in CdS/CdSe QDSSCs. As a result, their short-circuit current and corresponding PCE are effectively enhanced. The PCE can reach up to $5.07 \%$, which is about $24 \%$ larger than that of the conventional CdS/ CdSe QDSSCs without LPP layer. The solar cells can work in dark for a while due to the long-lasting fluorescence of the LPP layer. This research provides an effective way to improve the PCE of QDSSCs, and finds the possibility for all-weather QDSSCs.
\end{abstract}

Keywords: quantum dot-sensitized solar cells, all-weather solar cells, long-persistence phosphors, power conversion efficiency

\section{INTRODUCTION}

The energy crisis is one of the most serious problems in the 21 st century. To meet the fast growth of energy demand, it is urgent to develop economical, efficient and sustainable clean energy such as solar energy, wind energy, geothermal energy and so on. Among them, solar energy has become an important part of the alternative energy sources, and photovoltaic conversion has attracted much attention for a long time $[1,2]$. As the third generation of solar cells, quantum dot-sensitized solar cells (QDSSCs) proposed in 1998 by Zaban et al. [3] has attracted extensive attention from academia to industry, due to the advantages of adjustable band gap, high molar extinction coefficient, multiple exciton generation effect, resistance to water and oxygen, low cost and simple process [4-8]. So far, the power conversion efficiency (PCE) of QDSSCs was still limited for practical applications [9]. The main obstacle is the low light absorption efficiency and high charge recombination rate [10-13]. To reach its theoretical performance, considerable studies have been carried out [14-16]. It is found that optimizing the efficiency of charge collection, reducing the charge recombination and promoting the separation of electronhole pairs are effective methods to improve the PCE of QDSSCs [17-21]. Moreover, expanding the light absorption range and enhancing the light absorption efficiency have significant effect on the PCE [22]. In fact, devices usually show moderate PCE in visible region [23], while the PCE in the ultraviolet and near-infrared regions are often limited [24]. Therefore, to extend the effective light absorption into a wider range of solar spectrum is recommended [25].

According to these strategies, Sun et al. [26] used longpersistence phosphors (LPPs) in QDSSCs, and the PCE was eventually increased to $1.22 \%$. It is well known that LPPs are down-conversion fluorescent materials which absorb and store energy from ultraviolet or short-wave visible light below $450 \mathrm{~nm}$, and release a variety of visible fluorescence in dark environment for a long period of time [27]. Many advantages of LPPs have been reported, such as short excitation time, long luminescence time, high brightness, high chemical stability and environmental friendliness [28,29]. Meanwhile, LPPs have been widely studied in silicon-based, perovskite and dye-sensitized solar cells [30-34]. Richards et al. [30,31] reported that the PCE of silicon solar cells modified with lightemitting materials can be improved by $10 \%$. Researchers introduced down-conversion materials into perovskite solar cells, which greatly improved the performance and

National \& Local Joint Engineering Laboratory for Optical Conversion Materials and Technology, School of Physical Science and Technology, Lanzhou University, Lanzhou 730000, China

"Corresponding authors (emails: maf@leu.edu.cn (Ma F); pengshl@lzu.edu.cn (Peng S)) 
stability of the devices $[33,34]$. For dye-sensitized solar cells, the fluorescence coating can greatly improve the stability and PCE of the devices [32]. Light conversion structural layer inside the device, not only enhances the light absorption intensity, but also has a positive effect on the carrier transport and restriction of charge recombination [26,35-39].

Although light conversion materials have been widely used in solar cells, there were few reports on the utilization of LPPs in co-sensitized QDSSCs. In this work, we carried out a systematic study on the LPP enhancement to CdS/CdSe QDSSCs. The multifunctional LPP layer not only improved the light absorption, but also accelerated the transfer of photoelectrons, contributing to a significant enhancement in the PCE of QDSSCs composed of $\mathrm{TiO}_{2} / \mathrm{QDs} / \mathrm{LPPs}$ photoanodes. In comparison, the multifunctional layers with three kinds of LPPs were also fabricated respectively. It was found that the PCE of the CdS/CdSe QDSSCs with olivine-emitting LPPs increased from $4.08 \%$ to $5.07 \%$, an almost $24 \%$ enhancement compared with the QDSSCs without LPP layer. It is worth noting that the LPPs emit fluorescence to drive devices to work in dark environments and create possibility for the all-weather QDSSCs.

\section{EXPERIMENTAL SECTION}

\section{Chemicals and materials}

Transparent conducting films of fluorine-doped tin oxide on glass substrates (FTO glass, $7-8 \Omega$ /square, transmittance $80 \%-82 \%)$ and titanium oxide $\left(\mathrm{TiO}_{2}\right.$, Degussa, $\left.\mathrm{P} 25\right)$ were purchased from OPV Tech Co. Ltd. Sulfur (S, AR, 200 mesh), cadmium nitrate tetrahydrate $\left(\mathrm{Cd}\left(\mathrm{NO}_{3}\right)_{2}\right.$. $4 \mathrm{H}_{2} \mathrm{O}$, AR, 98\%), cadmium acetate dihydrate $\left(\mathrm{Cd}\left(\mathrm{CH}_{3} \mathrm{COO}\right)_{2} \cdot 2 \mathrm{H}_{2} \mathrm{O}, \mathrm{AR}, 98 \%\right)$ and nitrilotriacetic acid trisodium salt monohydrate $\left(\mathrm{N}\left(\mathrm{CH}_{2} \mathrm{COONa}\right)_{3} \cdot \mathrm{H}_{2} \mathrm{O}, \mathrm{AR}\right.$, 98\%) were purchased from Sigma Aldrich Co. Ltd. Selenium powder (Se, 200 mesh, 99.999\%) and brass foil (alloy 260, $0.51 \mathrm{~mm}$ thick) were supported by Alfa Aesar Co. Ltd. Sodium sulfite anhydrous $\left(\mathrm{Na}_{2} \mathrm{SO}_{3}, \mathrm{AR}, 98 \%\right)$, sodium sulfide nonahydrate $\left(\mathrm{Na}_{2} \mathrm{~S} \cdot 9 \mathrm{H}_{2} \mathrm{O}, \mathrm{AR}, 98 \%\right)$, ethyl cellulose $\left(\left[\mathrm{C}_{6}+2 n \mathrm{H}_{7}+8 n \mathrm{O}_{2}+4 n\right]_{x}, \mathrm{AR}\right)$ and terpineol $\left(\mathrm{C}_{10} \mathrm{H}_{18} \mathrm{O}, 95 \%\right)$ were provided by Aladdin Co. Ltd. Long persistence phosphors were purchased from Shenzhen Xiang Cai Luminous Material Co. Ltd. Methanol $\left(\mathrm{CH}_{4} \mathrm{O}\right.$, 99.5\%) and ethanol absolute $\left(\mathrm{C}_{2} \mathrm{H}_{6} \mathrm{O}, 99.8 \%\right)$ came from Ke-Long Chemical Reagent Co. Ltd.

\section{Preparation of quantum dot-sensitized photoanode}

The FTO glass was immersed into $300 \mathrm{~mL}$ of ethanol and deionized water in an ultrasonic cleaning machine for $20 \mathrm{~min}$, and then air-dried for later use. The solution was prepared by blending $7 \mathrm{~g}$ of terpineol, $2 \mathrm{~g}$ of $\mathrm{TiO}_{2}$ nanopowder and $2 \mathrm{~g}$ of ethyl cellulose in sequence with $100 \mathrm{~mL} \mathrm{C}_{2} \mathrm{H}_{6} \mathrm{O}$. After being stirred for $30 \mathrm{~min}$ with a magnetic stirrer and concentrated by rotary evaporation at $35^{\circ} \mathrm{C}$ for $5 \mathrm{~min}$, the mixture became creamy colloid. Porous $\mathrm{TiO}_{2}$ films were prepared by knife coating on the surface of the pre-cleaned FTO glasses and dried in a convection oven at $40^{\circ} \mathrm{C}$ for $20 \mathrm{~min}$. A mixture of $2 \mathrm{~g}$ of terpineol, $0.5 \mathrm{~g}$ of LPP powder and $0.5 \mathrm{~g}$ of ethyl cellulose in $10 \mathrm{~mL} \mathrm{C}_{2} \mathrm{H}_{6} \mathrm{O}$ was ground at $40^{\circ} \mathrm{C}$ for $30 \mathrm{~min}$. The porous fluorescent films on the surface of the porous structure were made by the same blade-coating and drying method. The area of the deposited $\mathrm{TiO}_{2} / \mathrm{LPPs}$ films was about $0.196 \mathrm{~cm}^{2}$, which was determined by an adhesive tape. Finally, the samples were calcined at $500^{\circ} \mathrm{C}$ for $30 \mathrm{~min}$ to eliminate excess ingredients. QDs of CdS and CdSe were prepared according to our previous processes [40].

\section{Preparation of electrolyte and counter electrode}

Solar cells were assembled by covering the quantum dotsensitized photoanode with a piece of brass with $\mathrm{Cu}_{2} \mathrm{~S}$ film as counter electrode. Polysulfide electrolyte was permeated into the assembly as electrolyte [40]. The electrolyte solution in this research was composed of $1 \mathrm{~mol} \mathrm{~L}^{-1}$ of $\mathrm{S}$ and $1 \mathrm{~mol} \mathrm{~L}^{-1}$ of $\mathrm{Na}_{2} \mathrm{~S} \cdot 9 \mathrm{H}_{2} \mathrm{O}$ in deionized (DI) water at a temperature of $50^{\circ} \mathrm{C}$ for $60 \mathrm{~min}$. A violent reaction between $37 \% \mathrm{HCl}$ solution and brass at $80^{\circ} \mathrm{C}$ for $40 \mathrm{~min}$ was used to clean the counter electrodes. Then, they were rinsed with DI water and dried in air. Finally, the pretreated brass foil was immersed in fresh electrolyte for $15 \mathrm{~min}$ to form $\mathrm{Cu}_{2} \mathrm{~S}$ film nanostructure on the surface of brass foil.

\section{Characterization}

The photocurrent density-voltage $(J-V)$ curves were measured (Keithley 2400 source meter) under a solar simulator (Zolix, China) with an intensity of $100 \mathrm{~mW} \mathrm{~cm}^{-2}$ (AM 1.5G). Every $J-V$ curve was measured repeatedly at least 15 times by using different photoanodes and the same counter electrode to eliminate experimental errors. The morphology of photoanode was studied by field emission scanning electron microscopy (SEM, TESCAN MIRA3, Czech). The transmission, absorption and photoluminescence spectra were measured by UV-Vis spectrophotometer (Hitachi U-3900H, Japan) and spectrofluorophotometer (Shimadzu RF-5301pc, Japan), respectively. The electrochemical impedance spectro- 
scopy (EIS) was performed by using an electrochemical workstation (Chinstruments CHI760E, China). The monochromatic incident photon-to-electron conversion efficiency (IPCE) was obtained by using a quantum efficiency testing system (Zolix, SCS10-EXP-1700, China).

\section{RESULTS AND DISCUSSION}

Fig. 1a shows the diagram of the QDSSCs with a sandwich structure, made of quantum dot-sensitized $\mathrm{TiO}_{2}$ photoanode, polysulfide redox couple electrolyte and $\mathrm{Cu}_{2} \mathrm{~S}$ counter electrode. The photoelectronic conversion processes stem from light absorption by QDs for electron excitation. The LPPs located on the surface of the $\mathrm{TiO}_{2} /$ QDs film were introduced to the QDSSCs, as shown in Fig. 1b. Fig. 1c is an optical photograph of the photoanode in which $\mathrm{CdS} / \mathrm{CdSe}$ QDs have been deposited. A multifunctional LPP layer on the surface of the $\mathrm{TiO}_{2} /$ $\mathrm{CdS} / \mathrm{CdSe}$ film can be observed. From left to right, the structure of the photoanodes is $\mathrm{TiO}_{2} / \mathrm{QDs} /$ blue-emitting LPPs, $\mathrm{TiO}_{2} / \mathrm{QDs} /$ olivine-emitting LPPs, $\mathrm{TiO}_{2} / \mathrm{QDs} /$ redemitting LPPs and $\mathrm{TiO}_{2} / \mathrm{QDs}$, respectively. As shown in Fig. 1d, the FTO glass was placed towards the light source (AM 1.5G, $100 \mathrm{~mW} \mathrm{~cm}^{-2}$ ) for one minute, and fluorescence from the photoanodes was observed in dark environment. It can be found that the LPP layer radiates different fluorescence colors, indicating the LPPs have been excited by ultraviolet light and emitted long-wave light.

Fig. 2 displays top-view SEM images of the $\mathrm{TiO}_{2} / \mathrm{QDs}$ and $\mathrm{TiO}_{2} / \mathrm{QDs} / \mathrm{LPPs}$ photoanodes. Compared with the $\mathrm{TiO}_{2} / \mathrm{QDs}$ photoanode, the surface of the photoanode modified with LPPs is uniformly covered by many LPPs with different shapes. The particle sizes of the LPPs are between 1 and $20 \mu \mathrm{m}$ and many voids are between the adjacent particles, which provide channels for the for-
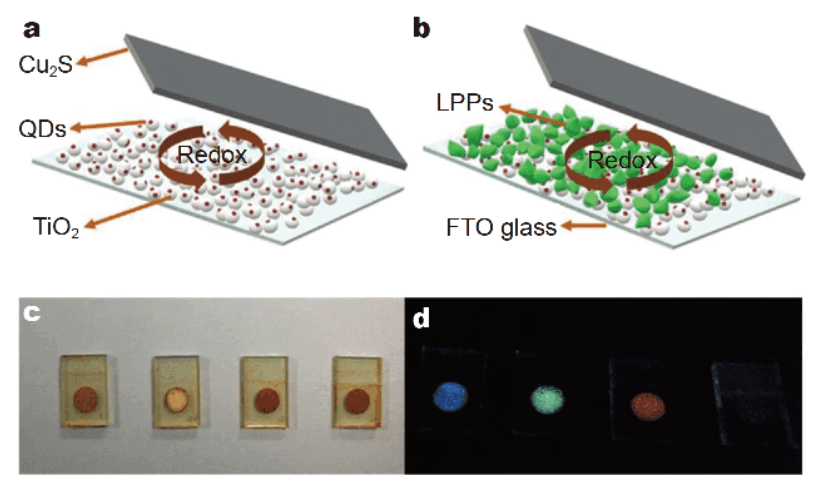

Figure 1 Schematic configuration of the QDSSCs (a) without and (b) with LPPs. The corresponding optical images of the photoanodes (c) in light and (d) in the dark.
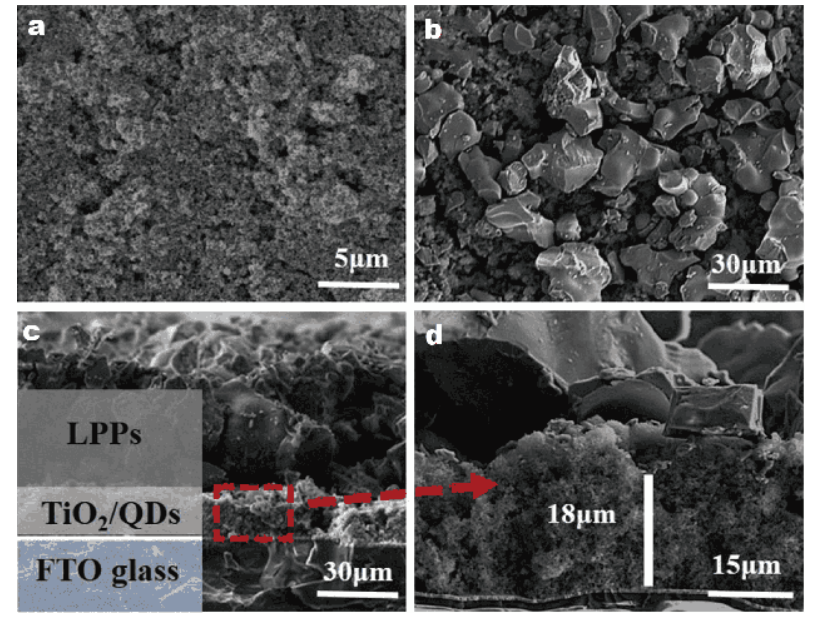

Figure 2 Top-view SEM images of (a) $\mathrm{TiO}_{2} / \mathrm{QDs}$ and (b) $\mathrm{TiO}_{2} / \mathrm{QDs} /$ olivine-emitting LPP photoanodes. Cross-sectional SEM images of (c) $\mathrm{TiO}_{2} /$ QDs/olivine-emitting LPP photoanode and (d) partial enlargement.

mation of QDs and the immersion of electrolyte in the $\mathrm{TiO}_{2}$ film. Fig. $2 \mathrm{c}$ depicts the cross-sectional view of the $\mathrm{TiO}_{2} / \mathrm{QDs} /$ olivine-emitting LPP photoanode. The LPP layer about $40 \mu \mathrm{m}$ thick is tightly bonded to the surface of the $\mathrm{TiO}_{2}$ film. And the $\mathrm{TiO}_{2}$ film with high specific surface area on the FTO glass is about $18 \mu \mathrm{m}$ thick, as shown in the partially enlarged view of the cross section in Fig. 2d. Fig. S1 shows the TEM images of the photoanode with LPPs with CdS and CdSe QDs on the surface of the mesoporous $\mathrm{TiO}_{2}$ film. Various crystal planes of QDs are clearly observed in the high-resolution image. The lattice spacing of 0.351 and $0.206 \mathrm{~nm}$ in polycrystalline particles matches the plane spacing of the (111) plane of cubic CdSe and the (220) plane of cubic CdS. Figs S2-S6 confirm the feature of the photoanode with LPPs. It is worth noting that the complex structure of LPP layer could prolong the route of light by light-reflection so that it might facilitate light absorption [41].

Transmission spectra of $\mathrm{TiO}_{2}$ and $\mathrm{TiO}_{2} / \mathrm{LPPs}$ films in the wavelength range of 350-750 $\mathrm{nm}$ are shown in Fig. 3a. The transmittance of $\mathrm{TiO}_{2} / \mathrm{LPPs}$ films is much lower than that of the conventional $\mathrm{TiO}_{2}$ films in the visible region. It is worth noting that the spectral transmittance of $\mathrm{TiO}_{2} /$ LPPs films is reduced from $74.6 \%$ to $29.9 \%$ in the nearinfrared band. Light-reflection is the main cause of longwavelength loss during transmission, which is consistent with previous reports $[42,43]$. Fig. $3 b$ shows the UV-Vis absorption spectra in the range of $350-750 \mathrm{~nm}$ of the photoanodes. Compared with the $\mathrm{TiO}_{2} / \mathrm{QDs}$ samples, the photoanodes based on $\mathrm{TiO}_{2} / \mathrm{QDs} / \mathrm{LPPs}$ structure have higher light absorption intensity, which benefits from the 

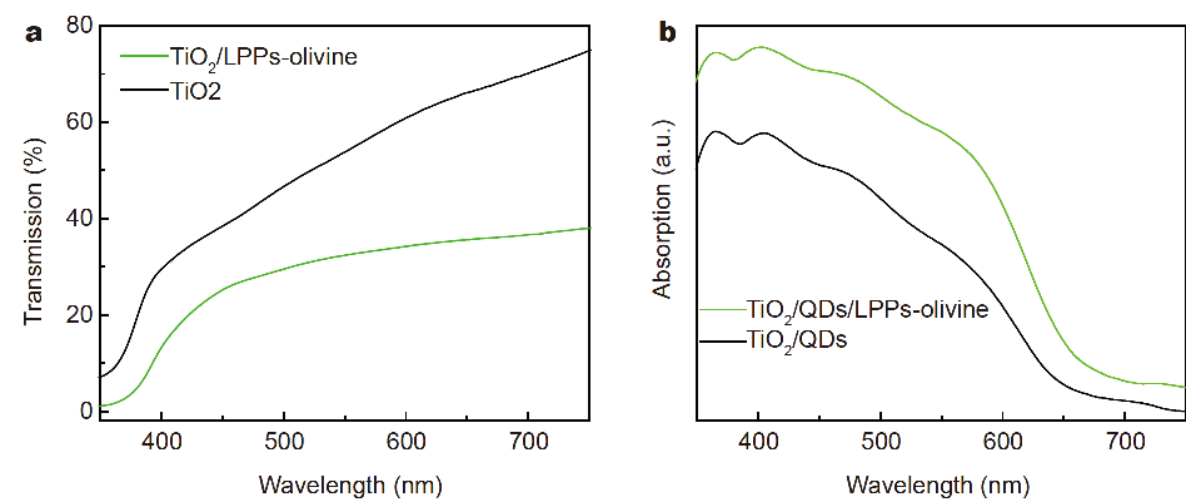

Figure 3 (a) Transmission and (b) UV-Vis absorption spectra of the photoanodes using FTO glass as benchmarks.

prolonged path of light propagation in the LPP layer and the reflection of long-wave light [41]. This speculation can be confirmed by the morphological features from the SEM images. Moreover, the absorption of UV light by LPPs below $400 \mathrm{~nm}$ leads to a decrease in light transmittance and an increase in light absorption intensity [39].

Fig. 4a shows the photoluminescence spectra of the olivine-emitting LPPs at room temperature with broad excitation peaks ranging from 250 to $450 \mathrm{~nm}$. And the excitation centers of the LPPs is $364 \mathrm{~nm}$. Correspond- ingly, LPP is excited by short-wave light to emit longwave light with a center of radiation at $574 \mathrm{~nm}$. It is found that long-wave fluorescent light from LPPs excited in ultraviolet range can be absorbed by QDs. So that it will increase the photocurrent density $\left(J_{\text {sc }}\right)$. Fig. $4 \mathrm{~b}$ depicts the IPCE spectra of the devices with and without LPP layer. The range of excitation and emission peaks for LPPs is represented by a rectangle of the corresponding color. It is obvious that the IPCE value of QDSSCs with LPP layer is always higher than that of the devices without LPPs. The increase in the short-wave range
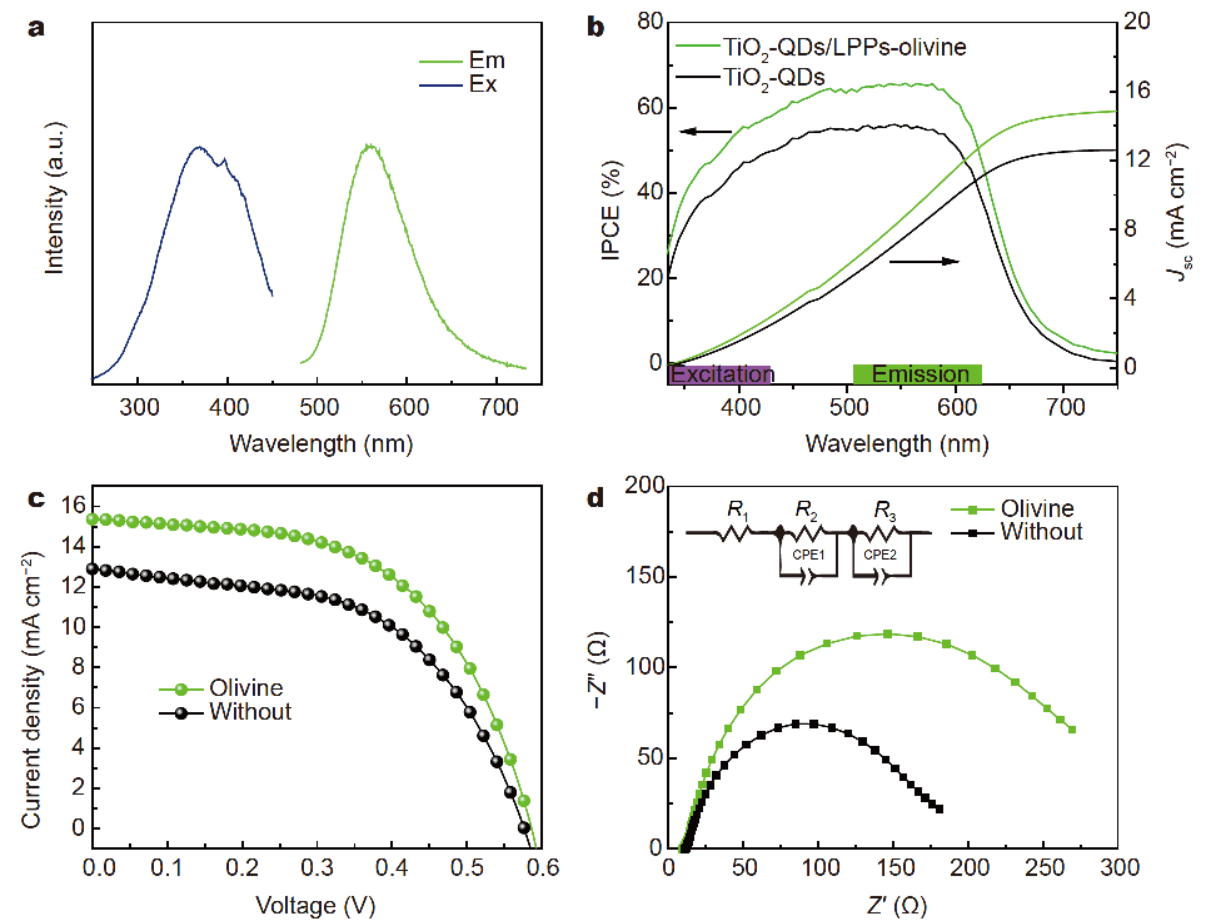

Figure 4 (a) Photoluminescence spectra of the olivine-emitting LPPs are obtained at room temperature. (b) IPCE spectra of QDSSCs, (c) current density-voltage $(J-V)$ curves and (d) EIS spectra. 
(below $450 \mathrm{~nm}$ ) is mainly due to the additional long-wave radiation provided by the LPPs, and this conclusion can be confirmed by the $J-V$ curve of Fig. S7. Meanwhile, the LPP layer reflects long-wave light, which also leads to an improvement in 450-750 nm, consistent with the related reports [26]. All IPCE values show a broad peak around the wavelength of $580 \mathrm{~nm}$. Therefore, for CdS/CdSe QDSSCs, the olivine light will be efficiently absorbed and converted by QDs of the as-prepared photovoltaic devices. Due to the friendly effect of LPP layer on lightharvesting, the QDSSCs containing LPP layer exhibit higher IPCE with the maximum value of $66 \%$, compared with the conventional QDSSCs (55\%). And, the $J_{\text {sc }}$ of QDSSCs was significantly enhanced, as shown in Fig. 4c. Meanwhile, the $J_{\mathrm{sc}}$ from IPCE integration is shown in Fig. $4 \mathrm{~b}$. The integral $J_{\mathrm{sc}}$ values of the samples with and without the LPPs are 14.85 and $12.6 \mathrm{~mA} \mathrm{~cm}^{-2}$, respectively, which are consistent with the $J_{\text {sc }}$ results of the $I-V$ test in Table 1 .

Fig. $4 \mathrm{~d}$ shows the EIS results of the photoanodes with and without LPPs. The EIS spectrum was carried out with direct current bias of $-0.6 \mathrm{~V}$ and alternative current amplitude of $10 \mathrm{mV}$ from $0.1 \mathrm{~Hz}$ to $100 \mathrm{kHz}$ in the dark. The corresponding outputs were fitted by Z-view software. The equivalent circuit of EIS is shown in the illustration of Fig. $4 \mathrm{~d}$ and the fitted values listed in Table $\mathrm{S} 1$, where $R_{1}$ is the substrate resistance, $R_{2}$ is the recombination resistance at the electrolyte-counter electrode interface and $R_{3}$ is the charge transfer resistance [44]. There is no obvious difference in $R_{2}$ due to the use of the same electrolyte and counter electrode during our experiments. Moreover, the data of charge transfer resistance $R_{3}$, for the photoelectron transfer process at $\mathrm{TiO}_{2} /$ QDs-electrolyte interface are larger than those of devices without LPP layer, ascribed to the reduced interfacial recombination, conducing to the improvement in fill factor (FF) and $J_{\mathrm{sc}}$, and which is consistent with related reports $[42,45-47]$. In particular, the IPCE value can be expressed as the following Equation (1):

IPCE $=\eta_{\text {LHE }} \times \eta_{\text {Inj }} \times \eta_{\text {cc }}$

where $\eta_{\text {LHE }}$ is the light-harvesting efficiency, $\eta_{\text {Inj }}$ is the charge-injection efficiency and $\eta_{\mathrm{cc}}$ is the charge-collection efficiency [48]. The light-harvesting efficiency $\eta_{\text {LHE }}$ is related to the light absorption intensity and can be derived by the following Equation (2) [49]:

$\eta_{\text {LHE }}=1-10^{\text {-absorbance }}$.

Equation (2) shows that efficient light absorption is beneficial to promoting the light-harvesting efficiency $\eta_{\text {LHE }}$. It is worth noting that the light absorption intensity of all QDSSCs with LPP layers is higher than that of the conventional QDSSCs, which improves the light-har- vesting efficiency $\eta_{\text {LHE }}$. The charge-injection efficiency $\eta_{\text {Inj }}$ depends on the stepped conduction band structure between the $\mathrm{TiO}_{2}$ particles and the QDs [38]. The driving force of electron transfer derived from the difference between the edges of the conduction band [50]. Obviously, the LPP layer does not change the conduction band position, and thus it does not affect the chargeinjection efficiency $\eta_{\text {Inj. }}$. As for charge-collection efficiency $\eta_{c c}$ it can be concluded that the LPP layer facilitates the charge transfer and reduces the interface recombination [51]. In short, the LPP layer improves both the chargecollection efficiency $\eta_{c c}$ and light-harvesting efficiency $\eta_{\text {LHE }}$, and thus the IPCE and $J_{\text {sc }}$ of the CdS/CdSe QDSSCs are increased [26].

Fig. 5a shows the $J-V$ characteristics of the CdS/CdSe QDSSCs with all kinds of LPPs. The $J_{\text {sc }}$ of the QDSSCs is significantly improved and the corresponding parameters are listed in Table 1. The $J_{\mathrm{sc}}$ increased from 12.89 to $15.36 \mathrm{~mA} \mathrm{~cm}^{-2}$, compared with the devices without the LPP layer. The FF increases slightly, and the highest PCE enhances from $4.08 \%$ to $5.07 \%$, an improvement of about $24 \%$. For clarity, the effects of LPPs on the $J_{\text {sc }}$ and PCE together with the corresponding deviation value of QDSSCs are illustrated in Fig. 5b. According to the above results, the $J_{\mathrm{sc}}$ and PCE of the QDSSCs are significantly improved, and the QDSSCs with the $\mathrm{TiO}_{2} / \mathrm{QDs} /$ olivineemitting LPPs photoanodes have the highest PCE, which is consistent with the conclusion of Fig. $4 \mathrm{~b}$.

The optical path diagram of the $\mathrm{TiO}_{2} / \mathrm{QDs} / \mathrm{LPPs}$ photoanodes is shown in Fig. 5c. The reason for the improvement of QDSSC performance can be summarized as follow: (1) LPP particles enhance the light-reflection, contributing to higher light-harvesting efficiency $\eta_{\mathrm{LHE}}$ of photoanodes. (2) The introduction of LPP layer facilitates the charge transfer and reduces the interface recombination, which has been confirmed by the EIS measurements. (3) LPPs are excited by short-wave ultraviolet light to emit long-wave light, which has been confirmed by the photoluminescence (PL) spectra. The long-wave light can be easily absorbed by CdS/CdSe QDs,

Table 1 Photoelectric parameters corresponding to different photoanodes in the device

\begin{tabular}{ccccc}
\hline Sample & $V_{\text {oc }}(\mathrm{V})$ & $\begin{array}{c}J_{\mathrm{sc}} \\
\left(\mathrm{mA} \mathrm{cm}^{-2}\right)\end{array}$ & $\mathrm{FF}$ & $\eta(\%)$ \\
\hline $\mathrm{TiO}_{2} / \mathrm{QDs} /$ Olivine & 0.59 & 15.36 & 0.56 & 5.07 \\
$\mathrm{TiO}_{2} / \mathrm{QDs} / \mathrm{Blue}$ & 0.59 & 14.35 & 0.57 & 4.82 \\
$\mathrm{TiO}_{2} / \mathrm{QDs} /$ Red & 0.59 & 13.80 & 0.56 & 4.58 \\
$\mathrm{TiO}_{2} / \mathrm{QDs}$ & 0.58 & 12.89 & 0.55 & 4.08 \\
\hline
\end{tabular}



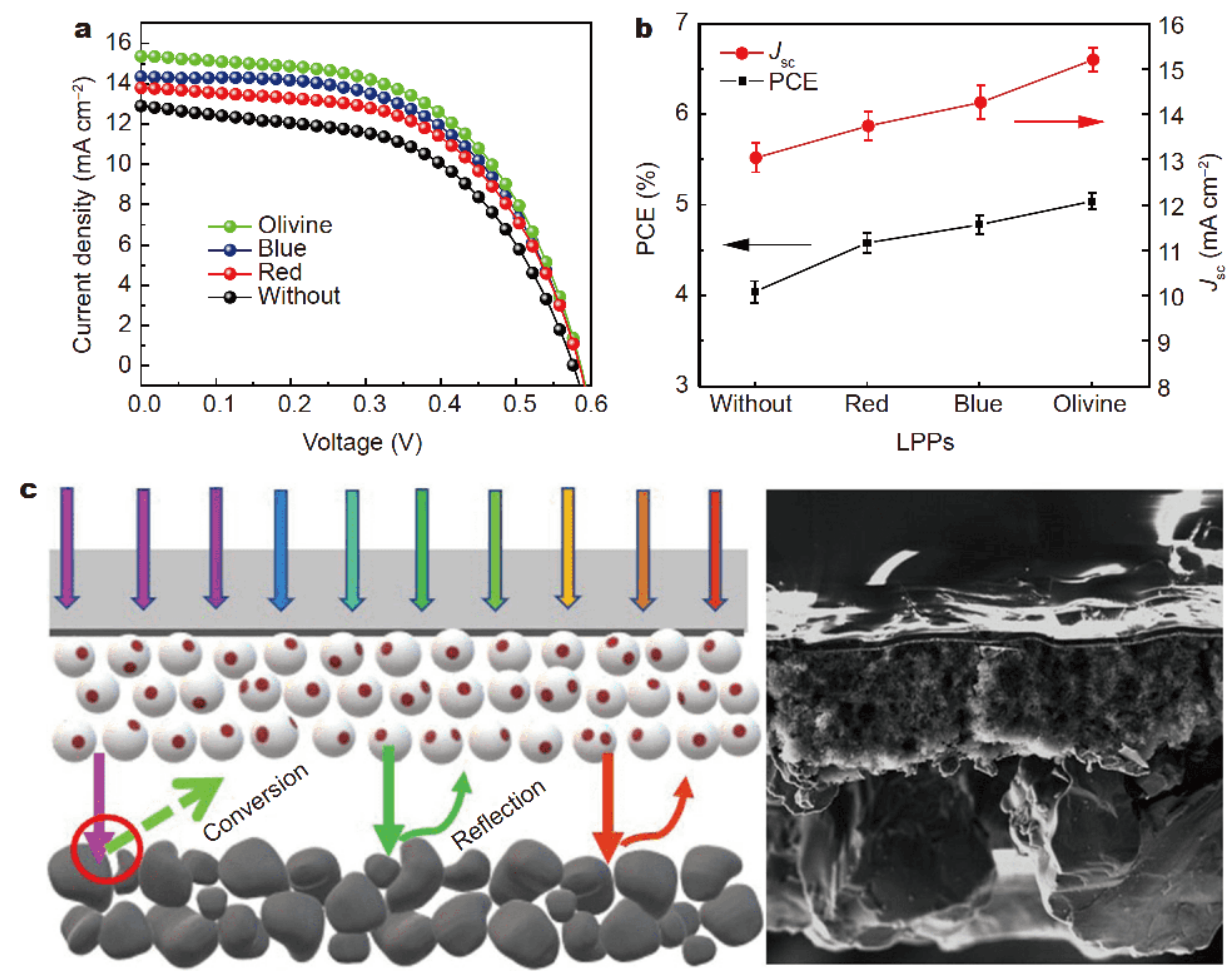

Figure 5 (a) Current density-voltage $(J-V)$ characteristics of the QDSSCs. (b) The dependence of the average PCE and $J_{\mathrm{sc}}$ on the kinds of LPPs in the modified photoanode and (c) light path diagram of the photoanodes with LPP layer.

thus improving the PCE of the CdS/CdSe QDSSCs, which has been confirmed by Fig. S8. Surprisingly, LPPs continue to emit fluorescence driving solar cells to work in the dark, creating possibility for all-weather solar cells. In general, the combination of the LPPs and QDSSCs can provide new opportunities for breakthroughs of QDSSCs performance.

\section{CONCLUSIONS}

The introduction of LPPs to the CdS/CdSe QDSSCs has been demonstrated to be an efficient and promising approach to significantly improve the PCE. The PL, UVVis, IPCE and EIS spectra investigations of the CdS/CdSe QDSSCs show that the LPPs can emit additional longwave light, enhance the light-reflection and reduce the interface recombination. It is found that the $J_{\mathrm{sc}}$ of $\mathrm{CdS} /$ CdSe QDSSCs with the olivine-emitting LPPs is significantly improved from 12.89 to $15.36 \mathrm{~mA} \mathrm{~cm}^{-2}$. And the PCE of the CdS/CdSe QDSSCs (5.07\%) is increased by $24 \%$ compared with the conventional solar cells $(4.08 \%)$. Also, the solar cells continue working in the dark after a solar illuminance (AM 1.5G) for one minute, showing their potential application.
Received 31 October 2019; accepted 7 January 2020; published online 20 January 2020

1 Grätzel M. Photoelectrochemical cells. Nature, 2001, 414: 338-344

2 Liu C, Cai $\mathrm{M}$, Yang $\mathrm{Y}$, et al. A $\mathrm{C}_{60} / \mathrm{TiO}_{x}$ bilayer for conformal growth of perovskite films for UV stable perovskite solar cells. J Mater Chem A, 2019, 7: 11086-11094

3 Zaban A, Mićić OI, Gregg BA, et al. Photosensitization of nanoporous $\mathrm{TiO}_{2}$ electrodes with InP quantum dots. Langmuir, 1998, 14: 3153-3156

4 Sambur JB, Novet T, Parkinson BA. Multiple exciton collection in a sensitized photovoltaic system. ChemInform, 2010, 41: 52-009

5 Cademartiri L, Montanari E, Calestani G, et al. Size-dependent extinction coefficients of PbS quantum dots. J Am Chem Soc, 2006, 128: 10337-10346

6 Tada H, Fujishima M, Kobayashi H. Photodeposition of metal sulfide quantum dots on titanium(IV) dioxide and the applications to solar energy conversion. Chem Soc Rev, 2011, 40: 4232-4243

7 Firoozi N, Dehghani H, Afrooz M. Cobalt-doped cadmium sulfide nanoparticles as efficient strategy to enhance performance of quantum dot sensitized solar cells. J Power Sources, 2015, 278: 98103

8 Yu WW, Qu L, Guo W, et al. Experimental determination of the extinction coefficient of CdTe, CdSe, and CdS nanocrystals. Chem Mater, 2003, 15: 2854-2860

9 Wang W, Feng W, Du J, et al. Cosensitized quantum dot solar cells with conversion efficiency over 12\%. Adv Mater, 2018, 30: 1705746

10 Rühle S, Shalom M, Zaban A. Quantum-dot-sensitized solar cells. 
ChemPhysChem, 2010, 11: 2290-2304

11 Tian J, Zhang Q, Zhang L, et al. $\mathrm{ZnO} / \mathrm{TiO}_{2}$ nanocable structured photoelectrodes for $\mathrm{CdS} / \mathrm{CdSe}$ quantum dot co-sensitized solar cells. Nanoscale, 2013, 5: 936-943

12 Pan Z, Rao H, Mora-Seró I, et al. Quantum dot-sensitized solar cells. Chem Soc Rev, 2018, 47: 7659-7702

13 Nozik AJ. Quantum dot solar cells. Phys E-Low-dimens Syst Nanostruct, 2002, 14: 115-120

14 Guo W, Zhang X, Yu R, et al. CoS NWs/Au hybridized networks as efficient counter electrodes for flexible sensitized solar cells. Adv Energy Mater, 2015, 5: 1500141-1500149

15 Wang $\mathrm{R}, \mathrm{Wu} \mathrm{X}, \mathrm{Xu} \mathrm{K}$, et al. Highly efficient inverted structural quantum dot solar cells. Adv Mater, 2018, 30: 1704882-1704886

16 Song $\mathrm{H}$, Rao H, Zhong X. Recent advances in electrolytes for quantum dot-sensitized solar cells. J Mater Chem A, 2018, 6: 48954911

17 Bai $\mathrm{H}$, Shen $\mathrm{T}$, Wang $\mathrm{S}$, et al. Controlled growth of $\mathrm{Cu}_{3} \mathrm{Se}_{2}$ nanosheets array counter electrode for quantum dots sensitized solar cell through ion exchange. Sci China Mater, 2017, 60: 637-645

18 Zhang $\mathrm{X}$, Zhang $\mathrm{J}$, Phuyal $\mathrm{D}$, et al. Inorganic $\mathrm{CsPbI}_{3}$ perovskite coating on $\mathrm{PbS}$ quantum dot for highly efficient and stable infrared light converting solar cells. Adv Energy Mater, 2018, 8: 1702049

19 Hou J, Zhao H, Huang F, et al. Facile one-step fabrication of $\mathrm{CdS}_{0.12} \mathrm{Se}_{0.88}$ quantum dots with a $\mathrm{ZnSe} / \mathrm{ZnS}$-passivation layer for highly efficient quantum dot sensitized solar cells. J Mater Chem A, 2018, 6: 9866-9873

20 Su L, Xiao Y, Han G, et al. Effective iron-molybdenum-disulfide counter electrodes for use in platinum-free dye-sensitized solar cells. Sci China Mater, 2018, 61: 1278-1284

21 Yang Y, Peng H, Liu C, et al. Bi-functional additive engineering for high-performance perovskite solar cells with reduced trap density. J Mater Chem A, 2019, 7: 6450-6458

22 Wang F, Yang M, Ji S, et al. Boosting spectral response of multicrystalline $\mathrm{Si}$ solar cells with $\mathrm{Mn}^{2+}$ doped $\mathrm{CsPbCl}_{3}$ quantum dots downconverter. J Power Sources, 2018, 395: 85-91

23 Li L, Yang Y, Fan R, et al. Conductive upconversion Er,Yb-FTO nanoparticle coating to replace $\mathrm{Pt}$ as a low-cost and high-performance counter electrode for dye-sensitized solar cells. ACS Appl Mater Interfaces, 2014, 6: 8223-8229

24 Rajeswari R, Susmitha K, Jayasankar CK, et al. Enhanced light harvesting with novel photon upconverted $\mathrm{Y}_{2} \mathrm{CaZnO}_{5}: \mathrm{Er}^{3+} / \mathrm{Yb}^{3+}$ nanophosphors for dye sensitized solar cells. Sol Energy, 2017, 157: 956-965

25 Yao N, Huang J, Fu K, et al. Enhanced light harvesting of dyesensitized solar cells with up/down conversion materials. Electrochim Acta, 2015, 154: 273-277

26 Sun H, Pan L, Piao X, et al. Enhanced performance of cadmium selenide quantum dot-sensitized solar cells by incorporating long afterglow europium, dysprosium co-doped strontium aluminate phosphors. J Colloid Interface Sci, 2014, 416: 81-85

27 Lin $\mathrm{Y}$, Zhang Z, Zhang F, et al. Preparation of the ultrafine $\mathrm{SrAl}_{2} \mathrm{O}_{4}: \mathrm{Eu}$,Dy needle-like phosphor and its optical properties. Mater Chem Phys, 2000, 65: 103-106

28 Han SD, Singh KC, Cho TY, et al. Preparation and characterization of long persistence strontium aluminate phosphor. J Lumin, 2008, 128: 301-305

29 Nag A, Kutty TRN. Role of $\mathrm{B}_{2} \mathrm{O}_{3}$ on the phase stability and long phosphorescence of $\mathrm{SrAl}_{2} \mathrm{O}_{4}: \mathrm{Eu}, \mathrm{Dy}$. J Alloys Compd, 2003, 354: 221-231

30 Richards BS. Luminescent layers for enhanced silicon solar cell performance: Down-conversion. Sol Energy Mater Sol Cells, 2006, 90: 1189-1207

31 Trupke T, Shalav A, Richards BS, et al. Efficiency enhancement of solar cells by luminescent up-conversion of sunlight. Sol Energy Mater Sol Cells, 2006, 90: 3327-3338

32 Bella F, Griffini G, Gerosa M, et al. Performance and stability improvements for dye-sensitized solar cells in the presence of luminescent coatings. J Power Sources, 2015, 283: 195-203

33 Bella F, Griffini G, Correa-Baena JP, et al. Improving efficiency and stability of perovskite solar cells with photocurable fluoropolymers. Science, 2016, 354: 203-206

34 Chen C, Li H, Jin J, et al. Long-lasting nanophosphors applied to UV-resistant and energy storage perovskite solar cells. Adv Energy Mater, 2017, 7: 1700758-1700765

35 Hafez H, Saif M, Abdel-Mottaleb MSA. Down-converting lanthanide doped $\mathrm{TiO}_{2}$ photoelectrodes for efficiency enhancement of dye-sensitized solar cells. J Power Sources, 2011, 196: 5792-5796

36 Roh J, Yu H, Jang J. Hexagonal $\beta-\mathrm{NaYF}_{4}: \mathrm{Yb}^{3+}, \mathrm{Er}^{3+}$ nanoprismincorporated upconverting layer in perovskite solar cells for nearinfrared sunlight harvesting. ACS Appl Mater Interfaces, 2016, 8: 19847-19852

37 Chander N, Khan AF, Chandrasekhar PS, et al. Reduced ultraviolet light induced degradation and enhanced light harvesting using $\mathrm{YVO}_{4}: \mathrm{Eu}^{3+}$ down-shifting nano-phosphor layer in organometal halide perovskite solar cells. Appl Phys Lett, 2014, 105: 033904

38 Ito S, Zakeeruddin SM, Comte P, et al. Bifacial dye-sensitized solar cells based on an ionic liquid electrolyte. Nat Photon, 2008, 2: 693698

39 Sun $\mathrm{H}$, Pan L, Piao X, et al. Long afterglow $\mathrm{SrAl}_{2} \mathrm{O}_{4}: \mathrm{Eu}, \mathrm{Dy}$ phosphors for CdS quantum dot-sensitized solar cells with enhanced photovoltaic performance. J Mater Chem A, 2013, 1: 6388-6392

40 Lu S, Peng S, Zhang Z, et al. Impacts of Mn ion in ZnSe passivation on electronic band structure for high efficiency CdS/CdSe quantum dot solar cells. Dalton Trans, 2018, 47: 9634-9642

41 Zhang Q, Guo X, Huang X, et al. Highly efficient CdS/CdSe-sensitized solar cells controlled by the structural properties of compact porous $\mathrm{TiO}_{2}$ photoelectrodes. Phys Chem Chem Phys, 2011, 13: 4659-4667

42 Zhu G, Pan L, Xu T, et al. Cascade structure of $\mathrm{TiO}_{2} / \mathrm{ZnO} / \mathrm{CdS}$ film for quantum dot sensitized solar cells. J Alloys Compd, 2011, 509: 7814-7818

43 Koo HJ, Park J, Yoo B, et al. Size-dependent scattering efficiency in dye-sensitized solar cell. Inorg Chim Acta, 2008, 361: 677-683

44 Yu J, Wang W, Pan Z, et al. Quantum dot sensitized solar cells with efficiency over $12 \%$ based on tetraethyl orthosilicate additive in polysulfide electrolyte. J Mater Chem A, 2017, 5: 14124-14133

45 Yang L, Zhou R, Lan J, et al. Efficient band alignment for $\mathrm{Zn}_{x} \mathrm{Cd}_{1-x}$ Se QD-sensitized $\mathrm{TiO}_{2}$ solar cells. J Mater Chem A, 2014, 2: $3669-3676$

46 Tang Q, Wang J, He B, et al. Can dye-sensitized solar cells generate electricity in the dark? Nano Energy, 2017, 33: 266-271

47 Zhang Z, Shi C, Xiao G, et al. All-solid-state quantum-dot-sensitized solar cells with compact $\mathrm{PbS}$ quantum-dot thin films and $\mathrm{TiO}_{2}$ nanorod arrays. Ceramics Int, 2017, 43: 10052-10056

48 Shin SS, Kim JS, Suk JH, et al. Improved quantum efficiency of highly efficient perovskite $\mathrm{BaSnO}_{3}$-based dye-sensitized solar cells. ACS Nano, 2013, 7: 1027-1035

49 Yum JH, Jang SR, Humphry-Baker R, et al. Effect of coadsorbent on the photovoltaic performance of zinc pthalocyanine-sensitized solar cells. Langmuir, 2008, 24: 5636-5640 
50 Huang F, Zhang Q, Xu B, et al. A comparison of $\mathrm{ZnS}$ and $\mathrm{ZnSe}$ passivation layers on CdS/CdSe co-sensitized quantum dot solar cells. J Mater Chem A, 2016, 4: 14773-14780

51 Fabregat-Santiago F, Bisquert J, Palomares E, et al. Correlation between photovoltaic performance and impedance spectroscopy of dye-sensitized solar cells based on ionic liquids. J Phys Chem C, 2007, 111: 6550-6560

Acknowledgements This work was financially supported by the National Natural Science Foundation of China (61376011, 51402141 and 61604086), Gansu Provincial Natural Science Foundation (17JR5RA198), the Fundamental Research Funds for the Central Universities (LZUJBKY-2018-119 and LZUJBKY-2018-CT08), Shenzhen Science and Technology Innovation Committee (JCYJ20170818155813437), and the Key Areas Scientific and Technological Research Projects in Xinjiang Production and Construction Corps (2018AB004).

Author contributions Deng $\mathrm{Y}$ and $\mathrm{Lu} \mathrm{S}$ designed and engineered the samples; Deng Y performed the experiments and data analysis; Deng Y wrote the paper with support from Ma F and Peng S; Deng Y, Ma F and Peng $S$ contributed to the theoretical analysis. Zhang $J$ provided the experimental materials and contributed to the theoretical analysis.

Conflict of interest The authors declare no conflict of interest.

Supplementary information

Supporting data are available in the online version of the paper.

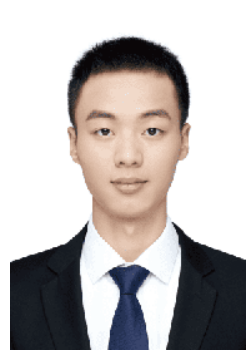

Yunlong Deng was awarded a bachelor's degree by Shenyang University of Science and Technology in 2017 . He is currently a graduate student in the School of Materials Science and Engineering at Lanzhou University. His main research interests are nanostructure design of quantum dot solar cells and flexible all-solidstate devices.

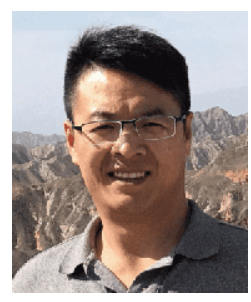

Shanglong Peng is a Professor of Lanzhou University. Since 2010, he has worked at the University of Washington, Seoul National University and the Hong Kong University of Science and Technology. Currently, he is mainly engaged in the design of nanomaterials, interface regulation and their applications in energy conversion and storage, including supercapacitors, solar cells and flexible wearable integrated energy conversion and storage integrated devices.

\section{长余辉苂光结构层增强CdS/CdSe量子点敏化太阳 能电池}

邓云龙, 路舒琦, 徐知源, 张家驰, 马飞 ${ }^{*}$, 彭尚龙 ${ }^{*}$

摘要 光吸收在提高量子点敏化太阳能电池(QDSSCs)的功率转换 效率(PCE)方面起着至关重要的作用. 本研究采用简单的刮涂法将 多功能长余辉苂光层 (LPP)引入到CdS/CdSe QDSSCs中. LPP层不 仅可以增强光的捕获, 还可以加速CdS/CdSe QDSSCs的电荷转移. 因此, LPP层的引入有效地提高了CdS/CdSe QDSSCs的短路电流密 度和相应的PCE. 当采用橄榄绿荧光层时, PCE高达 $5.07 \%$, 与常规 CdS/CdSe QDSSCs (4.08\%)的功率转换效率相比, PCE提高了 $24 \%$. 此外, 经过一分钟的太阳光照射( $\mathrm{AM} \quad 1.5 \mathrm{G}, 100 \mathrm{~mW} \mathrm{~cm}^{-2}$ ), 由于 LPPs的储能特性, 太阳能电池可在黑暗中继续工作. 本研究不仅为 QDSSCs提供了提高PCE的有效方法，而且为全天候QDSSCs的制备 提供了可能. 